\title{
Enriched Environment Confers Resistance to 1-Methyl-4- Phenyl-1,2,3,6-Tetrahydropyridine and Cocaine: Involvement of Dopamine Transporter and Trophic Factors
}

\author{
Erwan Bezard, ${ }^{1}$ Sandra Dovero, ${ }^{1}$ David Belin, ${ }^{2}$ Sophie Duconger, ${ }^{2}$ Vernice Jackson-Lewis, ${ }^{3}$ Serge Przedborski, ${ }^{3}$ \\ Pier Vincenzo Piazza, ${ }^{2}$ Christian E. Gross, ${ }^{1}$ and Mohamed Jaber ${ }^{4}$ \\ ${ }^{1}$ Basal Gang, Centre National de la Recherche Scientifique (CNRS) Unité Mixte de Recherche (UMR) 5543, Université Victor Segalen, 33076 Bordeaux \\ Cedex, France, ${ }^{2}$ Institut National de la Santé et de la Recherche Médicale 259, Institut François Magendie, 33077 Bordeaux Cedex, France, ${ }^{3}$ Departments of \\ Neurology and Pathology, Columbia University, New York, New York 10032, and ${ }^{4}$ CNRS UMR 6558, Université de Poitiers, 86022 Poitiers Cedex, France
}

We investigated, in mice, the influence of life experience on the vulnerability to 1-methyl-4-phenyl-1,2,3,6-tetrahydropyridine (MPTP), a major neurotoxin that induces a Parkinson's disease-like syndrome in humans, and to cocaine, a potent psychostimulant that promotes drug addiction. Our findings show that adult C57BL/6 mice raised in an enriched environment (EE) for only 2 months are significantly more resistant to both drugs compared with mice raised in a standard environment (SE). Indeed, EE mice showed decreased locomotor activity in response to cocaine $(10$ and $20 \mathrm{mg} / \mathrm{kg}$ ) as well as a different pattern of $c$-fos expression in the striatum compared with SE mice. After MPTP treatment, SE mice showed a 75\% loss of dopamine neurons, whereas EE mice showed only a $40 \%$ loss. The dopamine transporter plays a key role in mediating the effects of both drugs. We thus investigated the regulation of its expression. EE mice showed less dopamine transporter binding in the striatum and less dopamine transporter mRNA per dopamine neuron at the cellular level as demonstrated by in situ hybridization. In addition, enriched environment promoted an increase in the expression of brain-derived neurotrophic factor in the striatum. These data provide a direct demonstration of the beneficial consequences that a positive environment has in preventing neurodegeneration and in decreasing responsiveness to cocaine. Furthermore, they suggest that the probability of developing neurological disorders such as Parkinson's disease or vulnerability to psychostimulants may be related to life experience.

Key words: environmental enrichment; tyrosine hydroxylase; c-fos; dopamine transporter; BDNF; Parkinson's disease; drug of abuse

\section{Introduction}

Dopamine is a neurotransmitter that has been implicated in a wide variety of neurological and psychiatric disorders, including Parkinson's disease, attention-deficit hyperactivity disorder, schizophrenia, and drug abuse (for review, see Jaber et al., 1996). Dopamine neurotransmission is tightly controlled by its rapid reuptake through the dopamine transporter (DAT), a plasma membrane protein specific to dopamine neurons (Giros and Caron, 1993). We participated previously in the development of strains of mice lacking the DAT (Giros et al., 1996). Our results established not only the central importance of this transporter as the element key to maintaining a dopaminergic homeostasis (Jaber et al., 1999) but also its role in the behavioral and biochem-

\footnotetext{
Received May 30, 2003; revised Sept. 4, 2003; accepted 0ct. 1, 2003.

This work was supported by Centre National de la Recherche Scientifique (CNRS); Institut National de la Santé et de la Recherche Médicale; Region Aquitaine; National Institutes of Health and National Institute of Neurological Disorders and Stroke Grants R29 NS37345, R01 NS38586, R01 NS42269, and P50 NS38370; United States Department of Defense Grant DAMD 17-99-1-9471; the Parkinson's Disease Foundation; the Lowenstein Foundation; the Lillian Goldman Charitable Trust; the Muscular Dystrophy Association; the Amyotrophic Lateral Sclerosis Association; and Project Amyotrophic Lateral Sclerosis. We give special thanks to M. Cador for helpful advice and to D. Guilloteau for providing the dopamine transporter ligand (PE2I).

Correspondence should be addressed to Mohamed Jaber, Centre National de la Recherche Scientifique Unité Mixte de Recherche 6558, University de Poitiers, 40 Avenue Du Recteur Pineau, 86022 Poiters Cedex, France. E-mail: mohamed.jaber@univ-poitiers.fr.

Copyright $\odot 2003$ Society for Neuroscience ～0270-6474/03/2310999-09\$15.00/0
}

ical action of neurotoxins (Bezard et al., 1999; Fernagut et al., 2002) and of drugs of abuse (Spielewoy et al., 2000).

The etiology of brain diseases is often multifactorial and may be precipitated by inducers such as infective agents and neurotoxins. Unfortunately, the complex interactions between life experiences and the pathogenic effects of such a huge family of external events are currently unknown. For instance, life events such as stress, drug intake, or conditioned stimuli may have longterm repercussions on the whole organism and especially on the CNS (Nesse and Berridge, 1997; Nestler and Aghajanian, 1997). Several recent articles have provided striking evidence of the relevance of this issue to genetically induced brain diseases. Indeed, they show that life conditions can compensate for behavioral impairments provoked by two genetic mutations, one inducing motor disturbances mimicking Huntington's disease (Van Dellen et al., 2000) and the other a marked memory impairment (Rampon et al., 2000). An enriched environment combining both inanimate and social stimulation has also been shown to stimulate mammalian brain plasticity in dentate granule cell neurogenesis (Kempermann et al., 1997) and in glial cell proliferation (Walsh et al., 1969; Fiala et al., 1978).

Considering the well reported adaptive properties of mesencephalic dopaminergic neurons in various pathological situations (Zigmond and Stricker, 1985), we hypothesize that envi- 
ronmental conditions may prove beneficial in brain diseases affecting monoaminergic nuclei such as in drug addiction and Parkinson's disease. Here we describe the behavioral and molecular consequences of raising mice in an enriched environment (EE) and their differential response to a psychostimulant (cocaine) or to a pro-parkinsonian neurotoxin [1-methyl-4-phenyl1,2,3,6-tetrahydropyridine (MPTP)] compared with mice raised in a standard environment (SE). We show that EE decreases responsiveness to cocaine and protects against MPTP-induced neuronal loss. These effects would be mediated, at least in part, by a downregulation of the dopamine transporter, a mandatory target for psychostimulants (Jaber et al., 1996), and the obligatory neuronal gate to dopaminergic neurotoxins (Gainetdinov et al., 1997; Bezard et al., 1999). Furthermore, we suggest that this downregulation may be related, although not limited, to the upregulation of the brain-derived neurotrophic factor (BDNF).

\section{Materials and Methods}

Housing. Inbred C57BL/6 mice $(n=144)$ were used in this study and were housed in a temperature-controlled room under a $12 \mathrm{hr}$ light/dark cycle with ad libitum access to food and water. Experiments were performed in accordance with the European Communities Council Directive of November 24, 1986 (86/609/EEC) for the care of laboratory animals. The mice were raised together in groups of four after weaning (at 3 weeks of age) for 2 months either in an SE or in an EE. The SE consisted of common cage housing $(30 \times 15 \times 15 \mathrm{~cm})$. The EE constituted a larger $(75 \times 45 \times 25 \mathrm{~cm})$ cage constantly containing six to seven toys, which included a wheel and a small house that were randomly changed once per week (Rosenzweig and Bennett, 1996).

Cocaine treatments and locomotor activity measurement. After 2 months in either environmental condition, motor activity was measured in activity cages made of Plexiglas and aluminum wire mesh, as described previously (Deroche-Gamonet et al., 2003). Mouse locomotor responses to novelty were recorded during the first exposure to the activity cages. Mice were then acclimated to the activity cages for 2 consecutive days. On the fourth day, mice were first habituated to the activity cage for $50 \mathrm{~min}$ and then injected with the appropriate dose of saline vehicle (intraperitoneally) or cocaine (10 or $20 \mathrm{mg} / \mathrm{kg}$ ) (Cooperative Pharmaceutique Française, Melun, France). They were then returned to the activity cages for a 50 min period during which motor activity was recorded. At the end of the $50 \mathrm{~min}$ recording period, mice were taken into another room and killed by decapitation; their brains were then processed for in situ hybridization.

MPTP treatments and measurement of N-methyl-4-phenylpyridinium ion contents. After 2 months in either environmental condition, animals were treated either with MPTP $(20 \mathrm{mg} / \mathrm{kg}$, i.p. $)$ or with vehicle $(0.9 \%$ $\mathrm{NaCl}$ solution) using a schedule designed to induce a large dopaminergic lesion (four injections at $2 \mathrm{hr}$ intervals and a fifth injection $7 \mathrm{~d}$ later) as described previously (Gross et al., 2003; Meissner et al., 2003). All mice were killed $7 \mathrm{~d}$ after the last injection of MPTP (Jackson-Lewis et al., 1995). Brains were removed and processed for either immunohistochemistry, in situ hybridization, binding experiments, or $N$-methyl-4phenylpyridinium ion $\left(\mathrm{MPP}^{+}\right)$levels.

$\mathrm{MPP}^{+}$levels were determined as described previously (Przedborski et al., 1992). Both SE and EE mice were killed $2 \mathrm{hr}$ after a single intraperitoneal injection of MPTP $(20 \mathrm{mg} / \mathrm{kg})$. Brains were removed rapidly, and the caudate-putamen complex was dissected out on ice. Tissue samples were sonicated in $10 \mathrm{vol}$ of $5 \%$ trichloroacetic acid containing $20 \mu \mathrm{g} / \mathrm{ml}$ 4-phenylpyridine (Sigma, St. Louis, MO) as internal standard. Homogenates were centrifuged at $15,000 \times g$ for $20 \mathrm{~min}$ at $4^{\circ} \mathrm{C}$, and the contents of $\mathrm{MPP}^{+}$in the resulting supernatants were quantified by HPLC with $\mathrm{UV}$ detection. $\mathrm{MPP}^{+}$was monitored at $295 \mathrm{~nm}$, and flow rate was set at $1.5 \mathrm{ml} / \mathrm{min}$. Quantification was made by comparison of peak height ratios in the samples with those of the standards.

Stereology and counting of tyrosine hydroxylase-immunoreactive neurons. Free-floating mesencephalic serial sections were processed for TH immunohistochemistry and then counterstained with cresyl violet [Niss] staining (NS)] as described previously (Bezard et al., 1997). Cell counts were performed using a computer-based image analyzer (Visioscan v4.12; Biocom, Les Ulis, France). Unbiased stereological techniques were used to estimate cell numbers in the substantia nigra pars compacta (SNc) (Gundersen et al., 1988; West and Gundersen, 1990) as described previously (Gross et al., 2003; Meissner et al., 2003). Every fourth section of the SNc, the boundaries of which were chosen by examining the size and shape of the different TH-immunoreactive (TH-IR) neuronal groups and cellular relationships to axonal projections and nearby fiber bundles (German et al., 1996; Franklin and Paxinos, 1997), was counted. Volume was calculated using the following formula: $V_{(\mathrm{SNc})}=\Sigma S t d$; where $\Sigma S$ is the sum of surface areas, $t$ is the average section thickness, and $d$ is the distance between the sections (Theoret et al., 1999). Eight sections, the first being randomly chosen, were used, and optical dissectors were distributed using a systematic sampling scheme. Dissectors ( 50 $\mu \mathrm{m}$ length, $40 \mu \mathrm{m}$ width) were separated from each other by $30 \mu \mathrm{m}(x)$ and $20 \mu \mathrm{m}(y)$. In these dissectors, the nuclei of the neurons in focus were counted (Gundersen et al., 1988). To be counted, a neuron had to be entirely inside the dissector or lying across the dissector border by more than half its surface (Gundersen et al., 1988). Only two consecutive borders on four sides of the dissector were considered (Gundersen et al., 1988). The following formula was used to estimate the number of NS and TH-IR neurons: $n=V_{(\mathrm{SNc})}\left(\Sigma Q^{-} / \Sigma V_{(\mathrm{dis})}\right)$; where $n$ is the estimation of cell number, $V$ is the volume of the SNc, $\Sigma Q^{-}$is the number of cells counted in the dissectors, and $\Sigma V_{(\mathrm{dis})}$ is the total volume of the dissectors (Theoret et al., 1999). Mean estimated numbers of NS (structural marker) and TH-IR (phenotypical marker) neurons \pm SEM were then calculated for each group of mice.

In situ hybridization histochemistry. The in situ hybridization procedure was performed as described previously (Jaber et al., 1995; Bezard et al., 2001a; Gross et al., 2003; Meissner et al., 2003) with oligonucleotide probes designed to recognize the following: $\mathrm{D}_{1}$ dopamine receptor (D1R) (Dearry et al., 1990; Gross et al., 2003), $\mathrm{D}_{2}$ dopamine receptor (D2R, mix of three oligonucleotides) (Dal Toso et al., 1989; Gross et al., 2003), preproenkephalin-A (PPE-A) (Tang et al., 1983; Gross et al., 2003), preproenkephalin-B (PPE-B) (Nawa et al., 1984; Gross et al., 2003), preprotachykinin (PPT) (Nawa et al., 1984; Gross et al., 2003), DAT (Jaber et al., 1999), BDNF (Wong et al., 1997), full-length tyrosine kinase neurotrophin receptor ( $\mathrm{TrkB}^{\mathrm{TK}+}$ ) (Wong et al., 1997), the truncated form of the TrkB neurotrophin receptor (TrkB ${ }^{\mathrm{TK}-}$ ) (Wong et al., 1997), and c-fos (Deroche-Gamonet et al., 2003). Oligonucleotide probes were labeled by tailing using terminal deoxynucleotide transferase (Promega, Madison, WI) with ${ }^{35} \mathrm{~S}$-deoxy-ATP (NEN, Paris, France) at a specific activity of $2 \times 10^{9} \mathrm{cpm} / \mu \mathrm{g}$. Sections were allowed to hybridize at $42^{\circ} \mathrm{C}$ for $18 \mathrm{hr}$ in hybridization solution [ $50 \%$ formamide, $4 \times$ SSC, $10 \%$ dextran sulfate, $10 \mathrm{~mm}$ dithiothreitol, and labeled probe up to a final concentration of $3 \times 10^{6} \mathrm{cpm} / \mathrm{ml}$. After stringent washes, the slides were dehydrated and exposed to $\beta$-max Hyperfilm (Amersham Biosciences, Arlington Heights, IL) along with autoradiographic microscale standards (Amersham Biosciences) for $7 \mathrm{~d}$. For anatomical visualization and microautoradiographic analyses, sections were dipped into LM-1 liquid emulsion (Amersham Biosciences), diluted to one-third concentration with water, exposed in the dark for 6 weeks, and then developed and counterstained with hematoxylin. Grain counting was done at $50 \times$ magnification, and neurons that showed a grain density greater than background were considered positive. The final data were converted into amount of radioactivity using a calibration curve constructed with the brain paste standards. Samples from individual animals were always analyzed in triplicate.

Dopamine transporter binding. To identify dopaminergic nerve endings, radiolabeling of $\left[{ }^{125} \mathrm{I}\right](E)-N$-(3-iodoprop-2-enyl)-2 $\beta$-carbomethoxy- $3 \beta$ ( $4^{\prime}$-methylphenyl) nortropane (PE2I) was performed from the stannyl precursor according to a method described previously (Guilloteau et al., 1998). After purification, $\left[{ }^{125} \mathrm{I}\right] \mathrm{PE} 2 \mathrm{I}$ was obtained in a no-carrier-added form with a specific activity of $2000 \mathrm{Ci} / \mathrm{mmol}$. Sections were incubated for $90 \mathrm{~min}$ at $25^{\circ} \mathrm{C}$ in $\mathrm{pH} 7.4$ phosphate buffer [composed of the following (in mM): $10.14 \mathrm{NaH}_{2} \mathrm{PO}_{4}, 137 \mathrm{NaCl}, 2.7 \mathrm{KCl}$, and $1.76 \mathrm{KH}_{2} \mathrm{PO}_{4}$ ], containing $100 \mathrm{pm}\left[{ }^{125} \mathrm{I}\right] \mathrm{PE} 2 \mathrm{I}$ as described previously (Bezard et al., $2001 b, c)$. After washes and drying at room temperature, sections along 
with calibrated $\left[{ }^{125} \mathrm{I}\right]$ microscales (Amersham Biosciences) were exposed to $\beta$-radiation-sensitive film (Hyperfilm $\beta$-max; Amersham Biosciences) in $\mathrm{X}$-ray cassettes for $3 \mathrm{~d}$.

Analysis of autoradiographs. Densitomeric analyses of autoradiographs were performed using an image analysis system (Densirag V. D2.99; Biocom) as described previously (Bezard et al., 2001c; Gross et al., 2003; Meissner et al., 2003). The optical density was assessed in the rostral caudate-putamen (Franklin and Paxinos, 1997). Three sections per animal and per marker were analyzed by an examiner who was blind to the experimental condition. Optical densities were averaged for each animal and converted to amount of radioactivity bound compared with the standards. Mean \pm SEM bound radioactivity was then calculated for each group.

Statistical analysis. Statistical analyses were performed using a two-way ANOVA. If significant, ANOVAs were followed by post hoc $t$ tests corrected for multiple comparisons by the method of Bonferroni (Miller, 1981) or Newman-Keuls (for behavioral analyses). All data were normally distributed, and significance levels of $t$ test comparisons were adjusted for inequality of variances when appropriate. Statistical analyses of both $\mathrm{MPP}^{+}$content and the number of silver grains per cell were performed using the Mann-Whitney test given the low numbers of animals per group. These analyses were completed using Intercooled Stata 6.0 (Stata Corporation, College Station, TX). A probability level of 5\% ( $p<$ $0.05)$ was considered significant.

\section{Results}

\section{Enriched mice are less responsive to novelty}

When mice were first tested for locomotor reactivity, EE mice showed reduced locomotor activity in the new environment of measurement cages when compared with SE mice $\left(F_{(1,31)}=13.1\right.$; $p<0.001)$. Locomotor activity of mice raised in either environment decreased significantly with time $\left(F_{(11,341)}=69.64 ; p<\right.$ 0.0001 ) (Fig. 1a), which indicated habituation. No time $\times$ environment interaction was observed, suggesting that the decrease in locomotor activity with time was similar in both groups $(F<1)$.

Mice were then habituated to the locomotor activity cages for $2 \mathrm{hr}$ per day for 2 consecutive days. On the day mice were to receive a cocaine or saline injection, they were again placed in activity cages for $50 \mathrm{~min}$ and then given either solution. During this preinjection period, locomotor activity of mice raised in either environment was comparable $(F<1)$ (Fig. $1 b)$.

\section{Enriched mice are less responsive to cocaine}

After habituation, mice received either saline or cocaine injections (intraperitoneally) at 10 or $20 \mathrm{mg} / \mathrm{kg}$ (Fig. $2 a, c$ ). Repeatedmeasures ANOVA, with time being the within-subject factor, showed that cocaine increased locomotor activity at 10 and 20 $\mathrm{mg} / \mathrm{kg}\left(F_{(3,12)}=13.086 ; p<0.001\right.$ and $F_{(3,47)}=57.5 ; p<0.0001$, respectively). At both cocaine doses (10 and $20 \mathrm{mg} / \mathrm{kg}$ ), locomotor activity decreased significantly with time $\left(F_{(4,48)}=13.09 ; p<\right.$ 0.0001 and $F_{(4,188)}=36.16 ; p<0.0001$, respectively). In addition, we observed a time $X$ environment interaction after cocaine at 10 and $20 \mathrm{mg} / \mathrm{kg}\left(F_{(12,48)}=5.73 ; p<0.0001\right.$ and $F_{(12,188)}=11.86$; $p<0.0001$, respectively), suggesting that the decrease in locomotor activity with time was different in relation to the environment. Post hoc analyses (Newman-Keuls) also showed that the increase in locomotor activity observed in EE mice was significantly less pronounced than that observed in SE mice at both 10 and $20 \mathrm{mg} / \mathrm{kg}$ cocaine doses ( $p<0.05$ for both doses) (Fig. $2 b, d$ ). Thus, EE mice were less responsive to cocaine (10 and $20 \mathrm{mg} / \mathrm{kg}$ ) than SE mice (Fig. 2). There was no difference in mice treated with saline $(F<1)$ in relation to the environment.
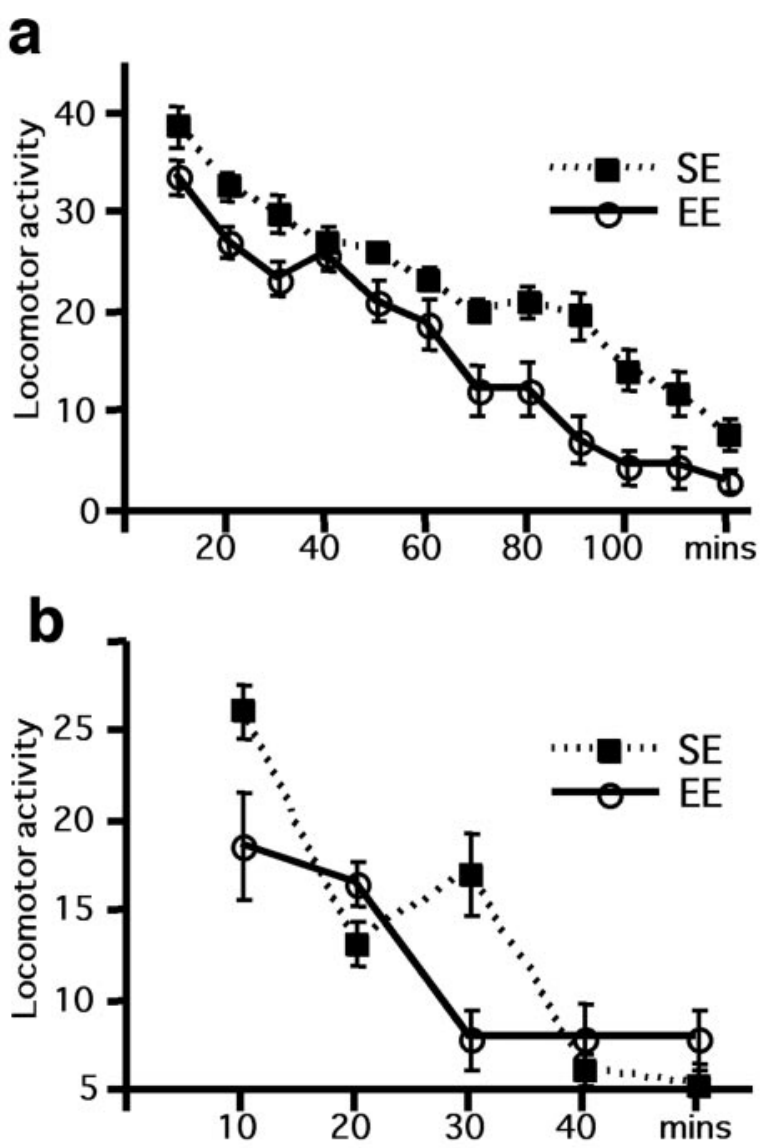

Figure 1. Mice raised in an enriched environment show decreased locomotor activity in response to novelty. Motor activity was measured in activity cages made of Plexiglas and aluminum wire mesh. Locomotor activity was measured every 10 min. $a, 0$ nday 1 , mice were put in measurement cages for $2 \mathrm{hr}$, and their locomotor response to novelty was measured during this first exposure. EE mice showed decreased locomotor activity compared with SE mice. $b$, Mice were acclimated to the activity cages for 2 consecutive days (days 2 and 3 ). The next day, they were again put in activity cages for $50 \mathrm{~min}$ before receiving cocaine. Note that the locomotor activity of SE and EE mice is not different before cocaine administration. Error bars are SEM.

\section{Enriched mice have a different c-fos expression pattern after cocaine injection}

Only a slight increase in c-fos expression was observed at 10 $\mathrm{mg} / \mathrm{kg}$ cocaine, and this increase was below the detection limits of the quantification procedure, also as observed previously (Johansson et al., 1994). A single injection of cocaine $(20 \mathrm{mg} / \mathrm{kg})$ increased c-fos mRNA levels coding for c-fos in the striata of both EE and SE mice (Fig. 3) $\left(F_{(1,15)}=8.08 ; p<0.05\right.$ and $F_{(1,12)}=6.34$; $p<0.05$, respectively). However, the pattern of $\mathrm{c}$-fos expression was different according to the environment. Indeed, whereas c-fos mRNA expression was increased mainly in the medioventral part of the striatum of SE mice (Fig. 3a,c), it was mainly present in the dorsolateral part of the striatum in EE mice (Fig. $3 b, d$ ).

\section{Enriched mice show decreased numbers of mesencephalic} dopamine neurons

Under control conditions, EE animals had $\sim 10 \%$ less dopaminergic neurons in the SNc than animals raised in SE (Fig. 4a). We also estimated the number of TH-IR neurons in the ventral tegmental area (VTA) to determine whether the lower numbers of $\mathrm{TH}-\mathrm{IR}$ neurons in the SNc of EE mice were attributable to postnatal neuronal migration differences as proposed by Lieb et al. (1996). Both SE $(8499 \pm 338)$ and EE $(8281 \pm 210)$ saline-treated 

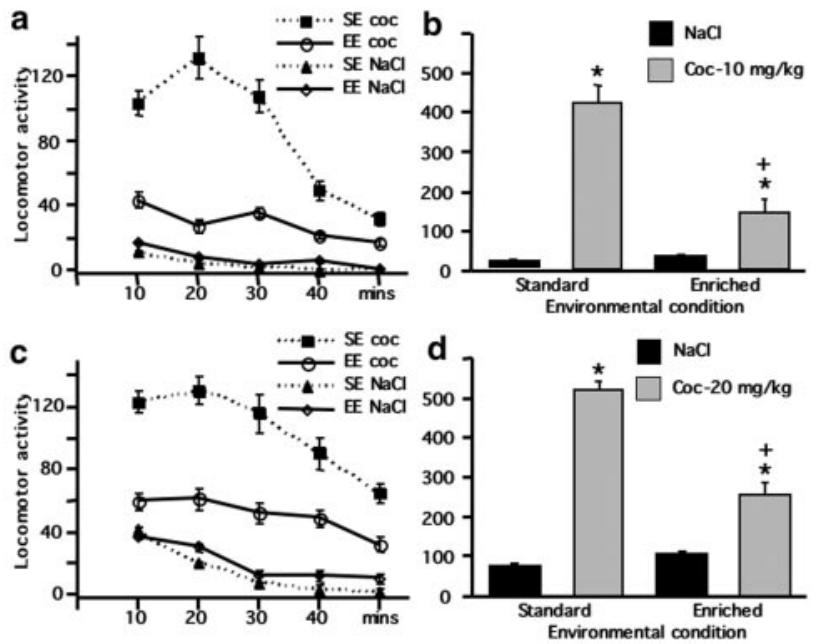

Figure 2. Mice raised in an enriched environment show decreased locomotor activity in response to cocaine (coc). Locomotor activity in SE or EE mice was measured after administration of $10 \mathrm{mg} / \mathrm{kg}$ cocaine $(a, b), 20 \mathrm{mg} / \mathrm{kg}$ cocaine $(c, d)$, or saline. Measurements were done every $10 \mathrm{~min}(a, c)$ and were also expressed with all time points pooled together $(c, d)$. At both doses, cocaine induced a significant increase in the locomotor activity in both SE and EE mice. Note, however, that EE mice were less responsive to cocaine than SE mice (see Results for details). * indicates significantly different from saline-treated animals; + indicates significantly different from cocaine-treated mice raised in an SE.
SE

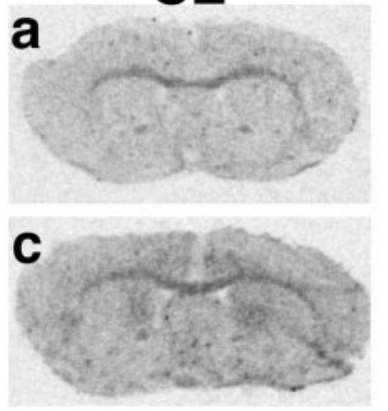

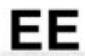

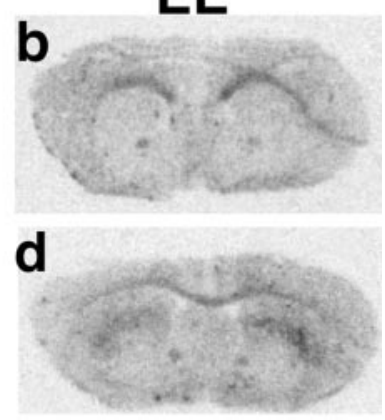

Figure 3. Cocaine-induced c-fos expression was altered in enriched mice. Saline treatment did not induce c-fos mRNA in our experimental protocol in either SE or EE mice after in situ hybridization. However, cocaine $(20 \mathrm{mg} / \mathrm{kg})$ significantly induced c-fos expression in both groups of mice, although in different striatal areas. Indeed, EE mice showed an expression restricted to dorsal areas that receive premotor and sensorimotor cortical projections, whereas SE mice showed expression in ventromedial areas, as found by most investigators working with mice housed in an SE and investigating c-fos mRNA (rather than protein). $a, b$, Saline-treated mice; $c, d$, cocaine-treated mice.

mice showed similar estimated numbers of TH-IR neurons within the VTA $(F<1)$. This indicates that the $10 \%$ decrease in $\mathrm{TH}-\mathrm{IR}$ neurons in the $\mathrm{SNc}$ of EE saline-treated mice could be the consequence of a higher neuronal elimination than a withinnuclei regulatory migration.

\section{Enriched mice are more resistant to MPTP}

A time interval of $7 \mathrm{~d}$ must be respected after MPTP exposure and before killing for the assessment of nigral degeneration by TH-IR neuronal count (phenotypical marker) in the mouse midbrain (Jackson-Lewis et al., 1995). However, because some cells can take up to 2 weeks to die, parallel counting of NS cells (structural marker) is required to control the validity of $\mathrm{TH}$ counting as a marker of cell death. After MPTP treatment, only $26.6 \%$ of

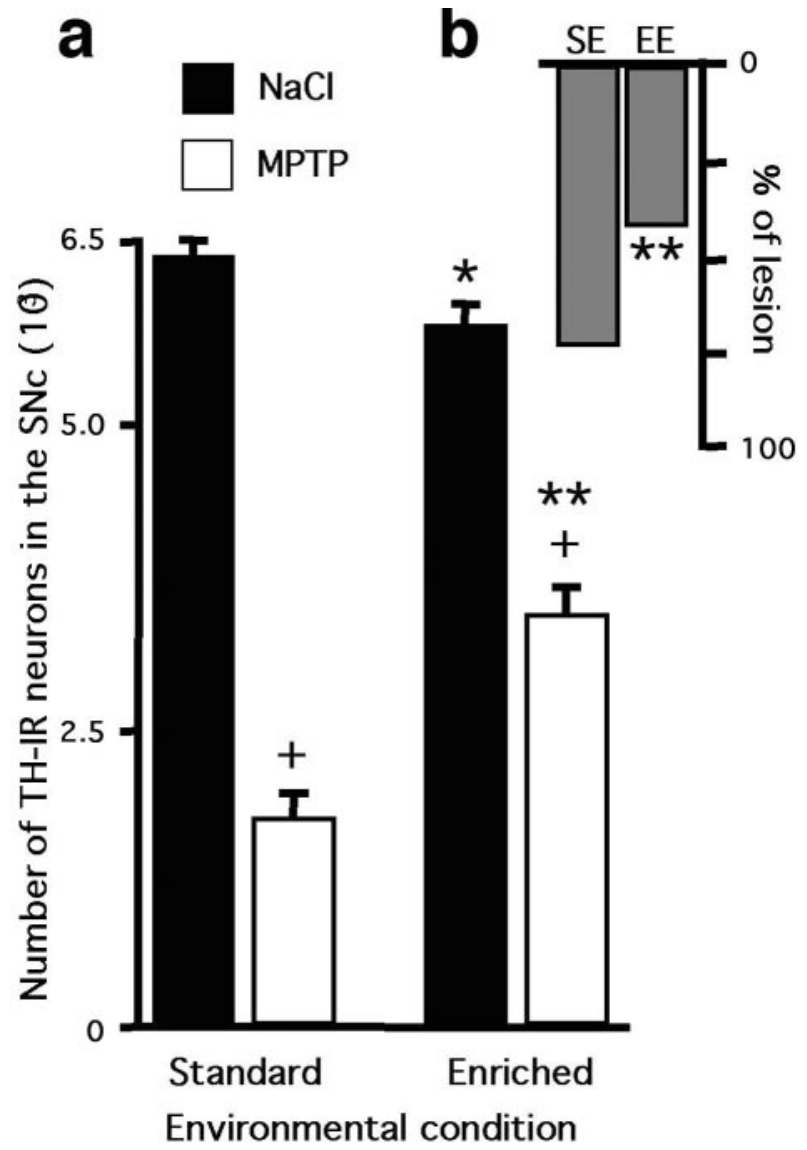

Figure 4. Living in an enriched environment provides protection against the proparkinsonian neurotoxin MPTP. a, Stereological counts of the number of TH-IR neurons in the SNc of saline- and MPTP-treated mice raised in SE or EE. Standard environment-NaCl, $n=6$; SE-MPTP, $n=7$; EE-NaCl, $n=8$; EE-MPTP, $n=6$. The enriched environment modified the number of TH-positive neurons $\left(F_{(1,26)}=12.3 ; p<0.01\right)$ and interfered with the MPTP treatment $\left(F_{(1,26)}=52.1 ; p<0.0001\right)$. Under control conditions, animals raised in an enriched environment had a lower number of TH-IR neurons than animals raised under standard conditions ( ${ }^{*} p<0.05$ ). After MPTP treatment, although both groups showed significant decreases in the number of $\mathrm{TH}$-IR neurons compared with their respective controls $\left({ }^{+} p<0.05\right)$, the number of surviving neurons was twice as high in EE compared with SE animals (** $p<0.05)$. b, Thus, the MPTP-induced TH neuron loss was $73.4 \%$ in SE mice and $41 \%$ in EE mice. Errors bars are SEM.

TH-IR neurons of SE mice survived in accordance with previous studies using the same doses of MPTP in mice raised in standard housing conditions (Fig. 3a) (Gross et al., 2003; Meissner et al., 2003). Accordingly, NS cells drop from $6583 \pm 144$ in the saline-SE to $1747 \pm 179$ in the MPTP-SE.

In contrast, in EE animals, $58.5 \%$ of the TH-IR neurons survived (Fig. 4a), as confirmed by the drop in NS cells from $5962 \pm$ 134 in saline-EE to $3499 \pm 233$ in MPTP-EE. Because the TH-IR and the NS counts matched, the cell death was completed. Thus, enriched environment increased the resistance of EE mice to MPTP by $199.7 \%$ (Fig. $4 b$ ).

$\mathrm{MPP}^{+}$striatal content was not different $(p=0.23)$ in SE $(6.9 \pm 1.3 \mu \mathrm{g} / \mathrm{mg}$ tissue; $n=3)$ and $\mathrm{EE}(4.7 \pm 0.5 \mu \mathrm{g} / \mathrm{mg}$ tissue; $n=4$ ) between the two groups of mice that received a single injection of $20 \mathrm{mg} / \mathrm{kg}$ MPTP (Przedborski et al., 1992). Thus, the resistance to toxicity was not attributable to a lower delivery of MPTP to the brain after intraperitoneal injection, to reduced brain biotransformation of MPTP to $\mathrm{MPP}^{+}$, or to diminished striatal mitochondrial monoamine oxidase B activity. 
a
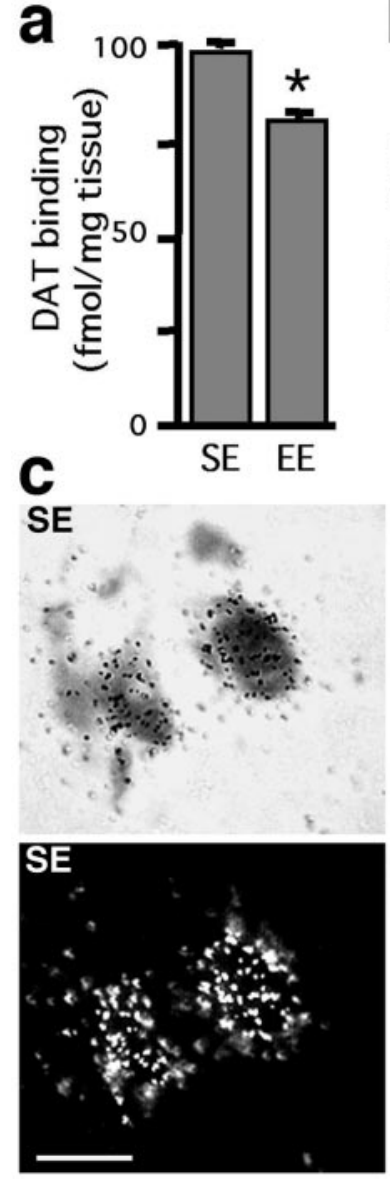

b

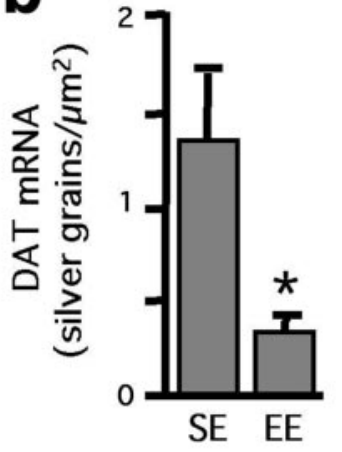

EE
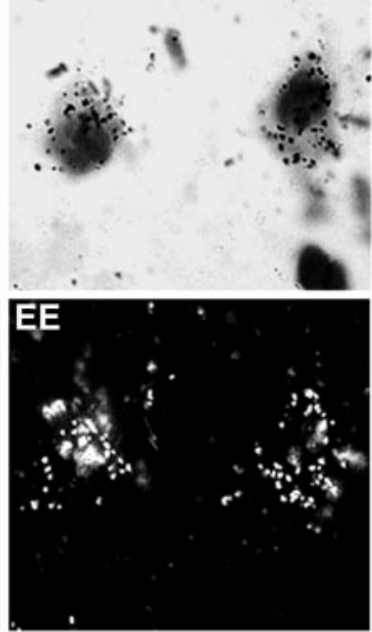

Figure 5. DAT binding is significantly decreased in the dorsal part of the striatum of EE mice $\left({ }^{*} p<0.05 ; \mathrm{SE}, n=8 ; \mathrm{EE}, n=8\right)$. $a$, The $100 \%$ level in SE mice corresponds to a PE2l binding of $97.8 \mathrm{fmol} / \mathrm{mg}$ equivalent tissue. $b$, This decrease is most likely attributable to lower number of DAT per neuron, because in situ hybridization for DAT mRNA showed a $75 \%$ silver grain decrease in EE compared with SE mice on microautoradiography. c, Photomicrographs of neurons labeled by in situ hybridization using oligonucleotide probes complementary to DAT mRNA and viewed under direct (top) and polarized (bottom) light illumination. Scale bar, $15 \mu \mathrm{m}$. Error bars are SEM.

\section{Decreased DAT expression may confer cocaine and MPTP resistance in $\mathrm{EE}$ mice}

The effects of both cocaine and MPTP are known to be mediated through the DAT (Jaber et al., 1997; Bezard et al., 1999). To determine the role of DAT in this differential resistance to MPTP-induced toxicity and cocaine-induced locomotor responsiveness as well as the implication of this resistance, we performed binding experiments using [ $\left.{ }^{125} \mathrm{I}\right] \mathrm{PE} 2 \mathrm{I}$ (Bezard et al., 2001c). Figure $5 a$ shows that raising mice in an EE downregulates the striatal levels of DAT in the saline-treated animals, regardless of the zone defined within the striatum (i.e., dorsal and ventral). Indeed, ANOVA indicates a significant effect of enrichment $\left(F_{(1,31)}=\right.$ $43.1 ; p<0.0001)$ but no effect of striatal zone $\left(F_{(1,31)}=1.4 ; p=\right.$ $0.25)$ and no interaction between enrichment and striatal zone $(F<1)$.

This decrease in DAT levels is most likely attributable to a decrease in the number of DAT binding sites per remaining dopamine neuron. We reached this conclusion in light of data obtained from DAT mRNA in situ hybridization at the microautoradiographic level. Indeed, grain counting corresponding to specific labeling of DAT mRNA allows the evaluation of the intensity of in situ labeling per cell. As shown in Figure 5, $b$ and $c$, we found that the grain density corresponding to DAT mRNA levels per cell was $75 \%$ lower in EE $(0.32 \pm 0.05)$ than in SE $(1.32 \pm$ $0.37)$ mice $(p=0.01)$. This suggests that mice raised in an enriched environment express much less DAT mRNA per dopamine neuron than mice raised in SE.

\section{Growth factor expression increases after enrichment}

BDNF is expressed in the mouse striatum (Wong et al., 1997; Guillin et al., 2001), the target area of substantia nigra dopamine neurons that were found to be decreased in EE mice. The substantia nigra is also a brain area in which DAT downregulation was observed in EE mice. For these reasons, because enrichment has been shown to induce expression of glial-derived neurotrophic factor and BDNF in the hippocampus (Young et al., 1999), and because simple motor enrichment also increases BDNF, we investigated the levels of mRNA expression of BDNF, TrkB ${ }^{\mathrm{TK}+}$, and $\mathrm{TrkB}^{\mathrm{TK}-}$ neurotrophin receptors in the striatum.

TrkB $^{\mathrm{TK}+}$ (Fig. 6a,b) and TrkB ${ }^{\mathrm{TK}-}$ (Fig. $\left.6 c, d\right)$ mRNA expression was not different in $\mathrm{EE}$ and $\mathrm{SE}$ mice $(F<1)$. BDNF, however, was increased in EE mice (e.g., $32.8 \pm 1.4 \mathrm{fmol} / \mathrm{mg}$ equivalent tissue in dorsal striatum) compared with SE mice (e.g., $21.4 \pm 1.2$ $\mathrm{fmol} / \mathrm{mg}$ equivalent tissue in dorsal striatum) (Fig. 6e,f). Indeed, ANOVA indicates a significant effect of enrichment $\left(F_{(1,31)}=\right.$ 62.42; $p<0.0001)$ but no effect of striatal zone $(F<1)$ and no interaction between enrichment and striatal zone $(F<1)$. Such an increase in BDNF expression suggests that the influence of the environment may be mediated through induction of growth factor expression.

\section{No difference in other dopamine-regulated markers in} relation to environment

Although the level of DAT was significantly affected by environmental conditions, the classical markers of dopamine transmission within the striatum were not. Indeed, $D_{1}$ (Fig. $6 g, h$ ) and $D_{2}$ (Fig. $6 i, j$ ) dopamine receptor mRNAs expression were not different between EE and SE mice $(F<1)$, regardless of the striatal area considered (e.g., the dorsolateral motor striatum or the nucleus accumbens). Expression of striatal PPE-A (Fig. 6k, l), PPE-B (Fig. $6 m, n$ ), and PPT (Fig. $6 o, p$ ) neuropeptide mRNA, known to be under the control of dopamine, was also not different between EE and SE mice $(F<1)$, further supporting the specificity of DAT regulation of expression within the nigrostriatal pathway.

\section{Discussion}

The present study shows that an enriched environment provides significant protection against both the locomotor and cellular effects of cocaine and MPTP-induced neurodegeneration. Such an effect probably involves an increase in expression of neurotrophic factors (e.g., BDNF as shown here) and a downregulation of the expression of DAT, the main target of psychostimulants and the neuronal gate to dopamine acting neurotoxins.

\section{Responsiveness to cocaine is under environmental control}

When raised in an enriched environment, C57BL/6 mice show reduced locomotor reactivity to a new environment compared with mice raised in an SE. Levels of activity in unfamiliar environments have been traditionally used as a measure of emotionality in rodents, although this is still a matter of debate (Day et al., 2001; Cabib et al., 2002). One obvious and very possible explanation of reduced activity in EE mice in a novel environment is that the measurement cages are much smaller and less attractive than their big home cages with renewed toys and social interaction.

From a molecular point of view, neurotoxins and psychoactive drugs produce their behavioral and cellular effects by acting 


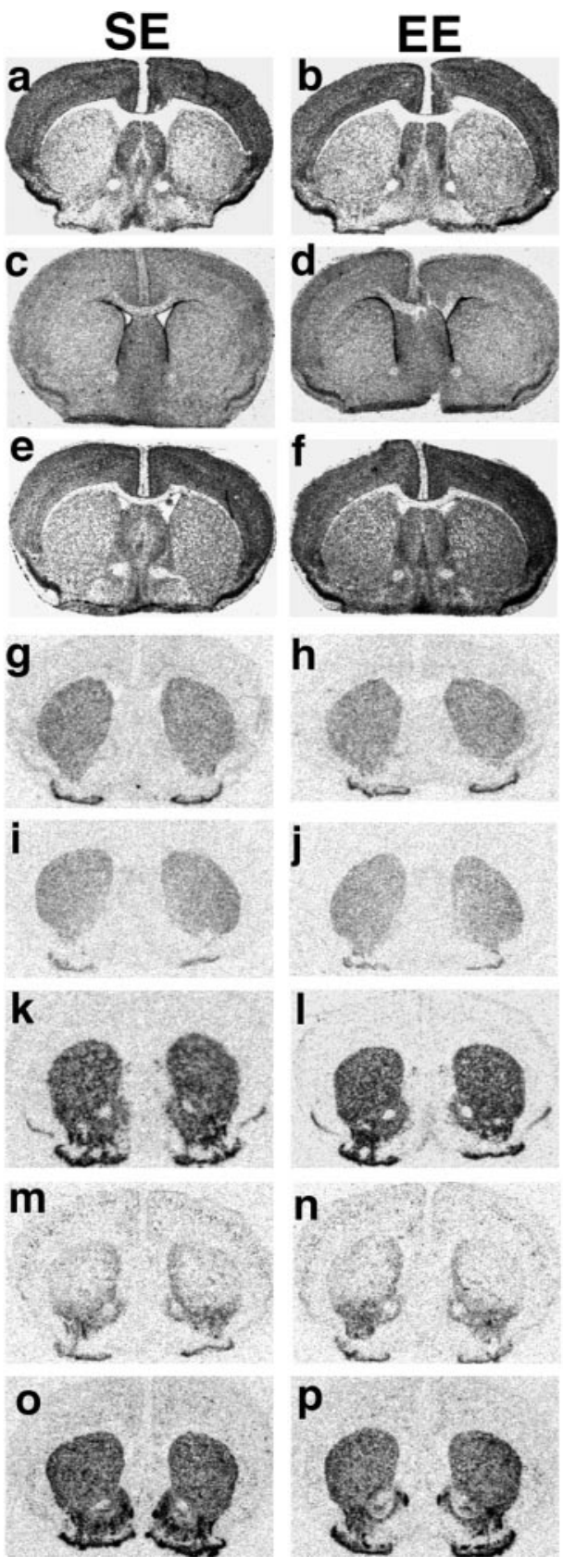

Figure 6. Enriched mice show increased expression of BDNF mRNA in the striatum as evidenced by in situ hybridization. Although the expression of both the full-length and the truncated form of the TrkB neurotrophin receptor [i.e., $\operatorname{TrkB}^{\mathrm{TK}+}(a, b)$ and $\operatorname{TrkB}^{\mathrm{TK}-}(c, d)$, respectively] is comparable in the SE and EE mice, BDNF mRNA expression $(e, f)$ is significantly increased throughout the brain and especially in the striatum of the mice living in the enriched environment. The mRNA expression of several dopamine-sensitive markers [i.e., D1R $(g, h)$, $\mathrm{D} 2 \mathrm{R}(i, j), \mathrm{PPE}-\mathrm{A}(k, l), \operatorname{PPE}-\mathrm{B}(m, n)$, and PPT $(0, p)]$ is not affected by the enriched environment.

at specific sites in the CNS, thus modifying neuronal targets (Nestler, 2001). This pharmacological explanation is confronted by several observations showing that drugs have different effects in relation to the circumstances related to their intake (Kelleher and Morse, 1968). Repetitive aggression of the organism may represent factors that predispose or precipitate drug selfadministration, thus creating situations that overwhelm the capacity of self-adjustment (Piazza and Le Moal, 1998). Inspired by Pavlovian conditioned reflexes, Wikler (1948) was among the first to propose the role of associative factors in drug addiction.
More recently, it has been demonstrated that a simple manipulation of the environment can modulate rats' reactions to an amphetamine injection. Indeed, rats showed increased locomotor activity when this drug is given in a novel environment (Badiani et al., 1995). In relation to the present study, environmental enrichment was shown previously to decrease intravenous amphetamine self-administration (Green et al., 2002). In accordance with these findings, we show that EE mice are less responsive to cocaine than SE mice. This finding suggests that initial personal experience may be crucial to determining resistance to drugs such as cocaine. Interestingly, EE mice show a different pattern of c-fos expression than SE mice after cocaine. c-fos mRNA was found mainly in ventromedial areas of the striatum of SE mice, as reported previously in studies using mice housed in an SE (Johansson et al., 1994). At variance, c-fos mRNA was expressed mostly in dorsolateral striatal regions in EE mice. Molecular changes in basal ganglia circuits are thought to play a crucial role in psychostimulant addiction and dependence (for review, see Nestler, 2001). An important determinant of striatal gene expression after psychostimulant treatments seems to be the excitatory input from the cortex (Cenci and Bjorklund, 1993). Dorsal striatal regions receive inputs mostly from sensory and motor cortical areas, suggesting that medial agranular (premotor) cortex and sensorimotor circuits are primarily involved in decreased cocaine response in EE mice.

\section{Enriched environment and neuroprotection}

Environmental enrichment can promote neuroplasticity and protect neurons, because evidence shows that these types of environments can promote increases in the complexity of dendritic arbors and synapses in the hippocampus and cerebellum (Black et al., 1989; Kleim et al., 1997) that can prevent age-related synaptic loss (Saito et al., 1994) and improve learning and memory (Kempermann et al., 1997; Nilsson et al., 1999; Young et al., 1999). Most if not all studies regarding the effects of enriched environment on neuronal injury and recovery after injury have focused on the cortical and hippocampal areas, long known to be responsive to environmental modifications. For instance, EE rats display less severe functional deficits caused by bilateral lesions of the frontal cortex in relation to reduced structural damage (Kolb and Gibb, 1991) and a better outcome after stroke (Johansson, 1996). Young et al. (1999) have also shown that enriched environment protects against excitotoxic injuries in a model of epilepsy. Nonetheless, this protection was chiefly the result of the prevention of kainate-induced seizures, because seizure duration is an essential determinant of the extent of neuronal injury in the hippocampus (Lothman and Bertram, 1993).

Although the overall impact of enriched environment on the brain circuitry of the dopamine system has not yet been investigated, the effects of motor activity on dopamine neuronal death have recently received attention. Indeed, forced limb use (i.e., a sort of motor enrichment) specifically renders dopamine neurons resistant to dopamine neurotoxins (Tillerson et al., 2001; Cohen et al., 2003), whereas forced nonuse (i.e., a motor impoverishment) does the opposite (Tillerson et al., 2002). In addition, physical activity has been shown to induce growth factor expression (Neeper et al., 1995; Gomez-Pinilla et al., 1997; Cohen et al., 2003), as reported here. Therefore, it is possible that the increased home-cage activity in the EE mice (in contrast to activity in a novel environment) may have been beneficial in that immediately after neurotoxin exposure, motor behavior can reduce neurotoxicity (Tillerson et al., 2001), whereas MPTP-related reduc- 
tions in activity are likely to have exaggerated terminal loss (Tillerson et al., 2002).

\section{Specific regulation of DAT expression}

The magnitude of the protection that we report here is surprisingly elevated compared with pharmacological approaches aimed at reaching the same goal (for review, see Dawson and Dawson, 2002). Furthermore, we used a particularly demanding intoxication regimen to produce a severe lesion of the mesencephalic region (Gross et al., 2003; Meissner et al., 2003). To the best of our knowledge thus far, none of the hitherto proposed compounds have been tested using such a demanding paradigm that is supposed to overcome their neuroprotective capacity.

Because cocaine is a blocker of the DAT (Gonon et al., 2000) and MPTP is taken up by the same transporter (Gainetdinov et al., 1997) present exclusively on dopamine neurons (for review, see Giros and Caron, 1993), the DAT seemed to be a potential candidate for regulation by the environment on the basis of increased resistance to both drugs. Indeed, such a magnitude of neuroprotection could be achieved by blocking the DAT (Mayer et al., 1986) or by knocking out the DAT gene (Gainetdinov et al., 1997; Bezard et al., 1999). Using DAT knock-out mice, we demonstrated previously that the DAT is mandatory for MPTPinduced dopaminergic neurotoxicity (Gainetdinov et al., 1997; Bezard et al., 1999), and that it plays a crucial role in responsiveness to psychostimulants (Jaber et al., 1997; Gainetdinov et al., 1999).

The decrease in DAT binding that we observed may be attributable, at least in part, to the slight but significant $10 \%$ decrease in the number of dopamine neurons in the SNc (see below). However, such an explanation is ruled out by the fact that DAT mRNA expression was significantly reduced per nigral dopamine neuron, as we found by in situ hybridization at the microautoradiography level.

Many mechanisms are likely to mediate the effects of environment on both spontaneous and toxin-induced neuronal death. Inadequate trophic support from target-derived factors is known to play a role in physiological neuronal elimination. Exogenous administration or stimulus-induced expression of neurotrophic factors (e.g., through physical exercise) (Neeper et al., 1995) may increase the resilience of the brain to insults and neuronal damage (Gash et al., 1996; Bjorklund and Lindvall, 2000). As shown in the hippocampus of EE rats (Young et al., 1999) and in several brain structures of animals forced to exercise (Neeper et al., 1995; Gomez-Pinilla et al., 1997; Cohen et al., 2003), we report here an environmentally driven increase in BDNF expression in the striatum. Although such upregulated growth factor expression is unlikely limited to BDNF, the well known trophic factor activity of BDNF on dopamine neurons (Hyman et al., 1991) may play a role in DAT downregulation and in the subsequent resistance to MPTP and cocaine. A systematic investigation of EE on growth factor expression is needed to further characterize the respective role of these factors in this phenomenon.

\section{SNc neurons are downregulated in EE mice}

Perhaps one of the most intriguing findings is that mice raised in an EE, supposedly a positive environment that would prevent cell loss (Young et al., 1999), show 10\% less TH-positive neurons in the SNc compared with mice raised in an SE. One possible explanation may rely on differential cell death through apoptosis, as has been shown in the hippocampus (Young et al., 1999). During postnatal development, dopaminergic neurons of the substantia nigra undergo natural cell death that fulfils the criteria for apo- ptosis (Jackson-Lewis et al., 2000). This process seems to play a critical role in regulating adult numbers of dopaminergic neurons. Indeed, normal embryonic and postnatal development of specific neuronal circuits that underlie various behaviors (sensory, motor, or cognitive) includes cell death (for review, see Honig and Rosenberg, 2000). During this process, viability of neurons depends on whether they are properly connected. The fine tuning of neuronal connections at vulnerable periods during development appears to be orchestrated by environmental cues, including the microenvironments in which individual neurons find themselves. These cues control critical developmental processes such as proliferation, migration, differentiation, synaptogenesis, and myelination (for review, see Rice and Barone, 2000). Spatial, temporal, or quantitative errors in the stimuli that initiate programmed cell death can result in pathological neural development. This is observed not only in typical neurodegenerative disorders such as Alzheimer's disease and Huntington's disease but also in several neurodevelopmental disorders such as schizophrenia and autism. Thus, the slight but significant decrease in the number of dopamine neurons of the SNc in EE mice may have beneficial consequences and may participate in resistance to insult by neurotoxins later on.

\section{Conclusion}

This study focuses on the long-term influence of environmental manipulation during adolescence, a critical period of development. The models that we used provided evidence of neuronal plasticity at the molecular level that may underlie the decreased responsiveness of EE mice to both cocaine and MPTP. Although direct extrapolation of these findings and comparable data in human conditions is to be taken with caution, the discovery of the molecular mechanism by which environmental factors can induce phenotypic effects seems an essential step for developing relevant models of brain diseases and, subsequently, efficient therapies.

\section{References}

Badiani A, Browman KE, Robinson TE (1995) Influence of novel versus home environments on sensitization to the psychomotor stimulant effects of cocaine and amphetamine. Brain Res 674:291-298.

Bezard E, Dovero S, Bioulac B, Gross C (1997) Effect of different schedules of MPTP administration on dopaminergic neurodegeneration in mice. Exp Neurol 148:288-292.

Bezard E, Gross CE, Fournier MC, Dovero S, Bloch B, Jaber M (1999) Absence of MPTP-induced neuronal death in mice lacking the dopamine transporter. Exp Neurol 155:268-273.

Bezard E, Ravenscroft P, Gross CE, Crossman AR, Brotchie JM (2001a) Upregulation of striatal preproenkephalin gene expression occurs before the appearance of parkinsonian signs in 1-methyl-4-phenyl-1,2,3,6tetrahydropyridine monkeys. Neurobiol Dis 8:343-350.

Bezard E, Boraud T, Chalon S, Brotchie JM, Guilloteau D, Gross CE (2001b) Pallidal border cells: an anatomical and electrophysiological study in the MPTP-treated monkey. Neuroscience 103:119-125.

Bezard E, Dovero S, Prunier C, Ravenscroft P, Chalon S, Guilloteau D, Bioulac B, Brotchie JM, Gross CE (2001c) Relationship between the appearance of symptoms and the level of nigrostriatal degeneration in a progressive MPTP-lesioned macaque model of Parkinson's disease. J Neurosci 21:6853-6861.

Bjorklund A, Lindvall O (2000) Parkinson disease gene therapy moves toward the clinic. Nat Med 6:1207-1208.

Black JE, Sirevaag AM, Wallace CS, Savin MH, Greenough WT (1989) Effects of complex experience on somatic growth and organ development in rats. Dev Psychobiol 22:727-752.

Cabib S, Puglisi-Allegra S, Ventura R (2002) The contribution of comparative studies in inbred strains of mice to the understanding of the hyperactive phenotype. Behav Brain Res 130:103-109.

Cenci MA, Bjorklund A (1993) Transection of corticostriatal afferents re- 
duces amphetamine- and apomorphine-induced striatal fos expression and turning behaviour in unilaterally 6-hydroxydopamine-lesioned rats. Eur J Neurosci 5:1062-1070.

Cohen AD, Tillerson JL, Smith AD, Schallert T, Zigmond MJ (2003) Neuroprotective effects of prior limb use in 6-hydroxydopamine-treated rats: possible role of GDNF. J Neurochem 85:299-305.

Dal Toso R, Sommer B, Ewert M, Herb A, Pritchett DB, Bach A, Shivers BD, Seeburg PH (1989) The dopamine D2 receptor: two molecular forms generated by alternative splicing. EMBO J 8:4025-4034.

Dawson TM, Dawson VL (2002) Neuroprotective and neurorestorative strategies for Parkinson's disease. Nat Neurosci [Suppl] 5:1058-1061.

Day HE, Badiani A, Uslaner JM, Oates MM, Vittoz NM, Robinson TE, Watson SJ, Akil H (2001) Environmental novelty differentially affects c-fos mRNA expression induced by amphetamine or cocaine in subregions of the bed nucleus of the stria terminalis and amygdala. J Neurosci 21:732-740.

Dearry A, Gingrich JA, Falardeau P, Fremeau Jr RT, Bates MD, Caron MG (1990) Molecular cloning and expression of the gene for a human D1 dopamine receptor. Nature 347:72-76.

Deroche-Gamonet V, Sillaber I, Aouizerate B, Izawa R, Jaber M, Ghozland S, Kellendonk C, Le Moal M, Spanagel R, Schutz G, Tronche F, Piazza PV (2003) The glucocorticoid receptor as a potential target to reduce cocaine abuse. J Neurosci 23:4785-4790.

Fernagut PO, Diguet E, Jaber M, Tison F (2002) Prolonged elevated dopamine levels increase striatal neurodegeneration: evidence from DAT knock-out mice. Eur J Neurosci 15:2053-2056.

Fiala BA, Joyce JN, Greenough WT (1978) Environmental complexity modulates growth of granule cell dendrites in developing but not adult hippocampus of rats. Exp Neurol 59:372-383.

Franklin KB, Paxinos G (1997) The mouse brain in stereotaxic coordinates. Orlando, FL: Academic.

Gainetdinov RR, Fumagalli F, Jones SR, Caron MG (1997) Dopamine transporter is required for in vivo MPTP neurotoxicity: evidence from mice lacking the transporter. J Neurochem 69:1322-1325.

Gainetdinov RR, Wetsel WC, Jones SR, Levin ED, Jaber M, Caron MG (1999) Role of serotonin in the paradoxical calming effect of psychostimulants on hyperactivity. Science 283:397-401.

Gash DM, Zhang Z, Ovadia A, Cass WA, Yi A, Simmerman L, Russell D, Martin D, Lapchak PA, Collins F, Hoffer BJ, Gerhardt GA (1996) Functional recovery in parkinsonian monkey treated with GDNF. Nature 380:252-255.

German DC, Nelson EL, Liang CL, Speciale SG, Sinton CM, Sonsalla PK (1996) The neurotoxin MPTP causes degeneration of specific nucleus $\mathrm{A} 8, \mathrm{~A} 9$, and $\mathrm{A} 10$ dopaminergic neurons in the mouse. Neurodegeneration 5:299-312.

Giros B, Caron MG (1993) Molecular characterization of the dopamine transporter. Trends Pharmacol Sci 14:43-49.

Giros B, Jaber M, Jones SR, Wightman RM, Caron MG (1996) Hyperlocomotion and indifference to cocaine and amphetamine in mice lacking the dopamine transporter. Nature 379:606-612.

Gomez-Pinilla F, Dao L, So V (1997) Physical exercise induces FGF-2 and its mRNA in the hippocampus. Brain Res 764:1-8.

Gonon F, Burie JB, Jaber M, Benoit-Marand M, Dumartin B, Bloch B (2000) Geometry and kinetics of dopaminergic transmission in the rat striatum and in mice lacking the dopamine transporter. Prog Brain Res 125:291-302.

Green TA, Gehrke BJ, Bardo MT (2002) Environmental enrichment decreases intravenous amphetamine self-administration in rats: dose-response functions for fixed- and progressive-ratio schedules. Psychopharmacology (Berl) 162:373-378.

Gross CE, Ravenscroft P, Dovero S, Jaber M, Bioulac B, Bezard E (2003) Pattern of levodopa-induced striatal changes is different in normal and MPTP-lesioned mice. J Neurochem 84:1246-1255.

Guillin O, Diaz J, Carroll P, Griffon N, Schwartz JC, Sokoloff P (2001) BDNF controls dopamine D3 receptor expression and triggers behavioural sensitization. Nature 411:86-89.

Guilloteau D, Emond P, Baulieu JL, Garreau L, Frangin Y, Pourcelot L, Mauclaire L, Besnard JC, Chalon S (1998) Exploration of the dopamine transporter: in vitro and in vivo characterization of a high-affinity and high-specificity iodinated tropane derivative $(E)-N$-(3-iodoprop-2enyl)- $2 \beta$-carbomethoxy-3 $\beta$-( $4^{\prime}$-methylphenyl) nortropane (PE2I). Nucl Med Biol 25:331-337.
Gundersen HJ, Bagger P, Bendtsen TF, Evans SM, Korbo L, Marcussen N, Moller A, Nielsen K, Nyengaard JR, Pakkenberg B, Sorensen FB, Vesterby A, West MJ (1988) The new stereological tools: disector, fractionator, nucleator and point sampled intercepts and their use in pathological research and diagnosis. APMIS 96:857-881.

Honig LS, Rosenberg RN (2000) Apoptosis and neurologic disease. Am J Med 108:317-330.

Hyman C, Hofer M, Barde YA, Juhasz M, Yancopoulos GD, Squinto SP, Lindsay RM (1991) BDNF is a neurotrophic factor for dopaminergic neurons of the substantia nigra. Nature 350:230-232.

Jaber M, Cador M, Dumartin B, Normand E, Stinus L, Bloch B (1995) Acute and chronic amphetamine treatments differently regulate neuropeptide messenger RNA levels and Fos immunoreactivity in rat striatal neurons. Neuroscience 65:1041-1050.

Jaber M, Robinson SW, Missale C, Caron MG (1996) Dopamine receptors and brain function. Neuropharmacology 35:1503-1519.

Jaber M, Jones S, Giros B, Caron MG (1997) The dopamine transporter: a crucial component regulating dopamine transmission. Mov Disord 12:629-633.

Jaber M, Dumartin B, Sagné C, Haycock JW, Roubert C, Giros B, Bloch B, Caron MG (1999) Differential regulation of tyrosine hydroxylase in the basal ganglia of mice lacking the dopamine transporter. Eur J Neurosci 11:3499-3511.

Jackson-Lewis V, Jakowec M, Burke RE, Przedborski S (1995) Time course and morphology of dopaminergic neuronal death caused by the neurotoxin 1-methyl-4-phenyl-1,2,3,6-tetrahydropyridine. Neurodegeneration 4:257-269.

Jackson-Lewis V, Vila M, Djaldetti R, Guegan C, Liberatore G, Liu J, O’Malley KL, Burke RE, Przedborski S (2000) Developmental cell death in dopaminergic neurons of the substantia nigra of mice. J Comp Neurol 424:476-488.

Johansson B, Lindstrom K, Fredholm BB (1994) Differences in the regional and cellular localization of c-fos messenger RNA induced by amphetamine, cocaine and caffeine in the rat. Neuroscience 59:837-849.

Johansson BB (1996) Functional outcome in rats transferred to an enriched environment 15 days after focal brain ischemia. Stroke 27:324-326.

Kelleher RT, Morse WH (1968) Determinants of the specificity of behavioral effects of drugs. Ergeb Physiol 60:1-56.

Kempermann G, Kuhn HG, Gage FH (1997) More hippocampal neurons in adult mice living in an enriched environment. Nature 386:493-495.

Kleim JA, Vij K, Ballard DH, Greenough WT (1997) Learning-dependent synaptic modifications in the cerebellar cortex of the adult rat persist for at least four weeks. J Neurosci 17:717-721.

Kolb B, Gibb R (1991) Environmental enrichment and cortical injury: behavioral and anatomical consequences of frontal cortex lesions. Cereb Cortex 1:189-198.

Lieb K, Andersen C, Lazarov N, Zienecke RR, Urban I, Reisert I, Pilgrim C (1996) Pre- and postnatal development of dopaminergic neuron numbers in the male and female mouse midbrain. Brain Res Dev Brain Res 94:37-43.

Lothman EW, Bertram III EH (1993) Epileptogenic effects of status epilepticus. Epilepsia 34 [Suppl 1]:S59-S70.

Mayer RA, Kindt MV, Heikkila RE (1986) Prevention of the nigrostriatal toxicity of 1-methyl-4-phenyl-1,2,3,6-tetrahydropyridine by inhibitors of 3,4-dihydroxyphenylethylamine transport. J Neurochem 47:1073-1079.

Meissner W, Bioulac B, Gross CE, Bezard E (2003) Within-basal ganglia compensatory mechanisms after striatal dopaminergic homeostasis breakdown. Neurobiol Dis 13:46-54.

Miller RG (1981) Simultaneous statistical inference, Ed 2. New York: Springer.

Nawa H, Kotani H, Nakanishi S (1984) Tissue-specific generation of two preprotachykinin mRNAs from one gene by alternative RNA splicing. Nature 312:729-734.

Neeper SA, Gomez-Pinilla F, Choi J, Cotman C (1995) Exercise and brain neurotrophins. Nature 373:109.

Nesse RM, Berridge KC (1997) Psychoactive drug use in evolutionary perspective. Science 278:63-66.

Nestler EJ (2001) Molecular basis of long term plasticity underlying addiction. Nat Rev Neurosci 2:119-128.

Nestler EJ, Aghajanian GK (1997) Molecular and cellular basis of addiction. Science 278:58-63.

Nilsson M, Perfilieva E, Johansson U, Orwar O, Eriksson PS (1999) En- 
riched environment increases neurogenesis in the adult rat dentate gyrus and improves spatial memory. J Neurobiol 39:569-578.

Piazza PV, Le Moal M (1998) The role of stress in drug self-administration. Trends Pharmacol Sci 19:67-74.

Przedborski S, Kostic V, Jackson-Lewis V, Naini AB, Simonetti S, Fahn S, Carlson E, Epstein CJ, Cadet JL (1992) Transgenic mice with increased $\mathrm{Cu} / \mathrm{Zn}$-superoxide dismutase activity are resistant to $\mathrm{N}$-methyl-4phenyl-1,2,3,6-tetrahydropyridine-induced neurotoxicity. J Neurosci 12:1658-1667.

Rampon C, Tang YP, Goodhouse J, Shimizu E, Kyin M, Tsien JZ (2000) Enrichment induces structural changes and recovery from nonspatial memory deficits in CA1 NMDAR1-knockout mice. Nat Neurosci 3:238-244.

Rice D, Barone Jr S (2000) Critical periods of vulnerability for the developing nervous system: evidence from humans and animal models. Environ Health Perspect 108 [Suppl 3]:511-533.

Rosenzweig MR, Bennett EL (1996) Psychobiology of plasticity: effects of training and experience on brain and behavior. Behav Brain Res 78:57-65.

Saito S, Kobayashi S, Ohashi Y, Igarashi M, Komiya Y, Ando S (1994) Decreased synaptic density in aged brains and its prevention by rearing under enriched environment as revealed by synaptophysin contents. J Neurosci Res 39:57-62.

Spielewoy C, Gonon F, Roubert C, Fauchey V, Jaber M, Caron MG, Roques BP, Hamon M, Betancur C, Maldonado R, Giros B (2000) Increased rewarding properties of morphine in dopamine-transporter knock-out mice. Eur J Neurosci 12:1827-1837.

Tang F, Costa E, Schwartz JP (1983) Increase of proenkephalin mRNA and enkephalin content of rat striatum after daily injection of haloperidol for 2 to 3 weeks. Proc Natl Acad Sci USA 80:3841-3844.
Theoret H, Boire D, Herbin M, Ptito M (1999) Stereological evaluation of substantia nigra cell number in normal and hemispherectomized monkeys. Brain Res 835:354-359.

Tillerson JL, Cohen AD, Philhower J, Miller GW, Zigmond MJ, Schallert T (2001) Forced limb-use effects on the behavioral and neurochemical effects of 6-hydroxydopamine. J Neurosci 21:4427-4435.

Tillerson JL, Cohen AD, Caudle WM, Zigmond MJ, Schallert T, Miller GW (2002) Forced nonuse in unilateral parkinsonian rats exacerbates injury. J Neurosci 22:6790-6799.

Van Dellen A, Blakemore C, Deacon R, York D, Hannan AJ (2000) Delaying the onset of Huntington's in mice. Nature 404:721-722.

Walsh RN, Budtz-Olsen OE, Penny JE, Cummins RA (1969) The effects of environmental complexity on the histology of the rat hippocampus. J Comp Neurol 137:361-366.

West MJ, Gundersen HJ (1990) Unbiased stereological estimation of the number of neurons in the human hippocampus. J Comp Neurol 296:1-22.

Wikler WA (1948) Recent progress in research on the neurophysical basis of morphine addiction. Am J Psychiatry 105:328-338.

Wong JY, Liberatore GT, Donnan GA, Howells DW (1997) Expression of brain-derived neurotrophic factor and TrkB neurotrophin receptors after striatal injury in the mouse. Exp Neurol 148:83-91.

Young D, Lawlor PA, Leone P, Dragunow M, During MJ (1999) Environmental enrichment inhibits spontaneous apoptosis, prevents seizures and is neuroprotective. Nat Med 5:448-453.

Zigmond MJ, Stricker EM (1985) Adaptive properties of monoaminergic neurons. In: Handbook of neurochemistry (Lajtha A, ed), pp 87-102. New York: Plenum. 